\title{
Becoming \\ visible in \\ meetings
}

Silje Graffer \& Alison Williams

A female colleague explained that when she was in a meeting and had raised an issue, people sort of nodded and half-agreed. However, when the same idea was raised later, and this time by a man (rephrased slightly), everyone was on board and gave him credit. She was left baffled. What was she to do - come off as 'bitter' or 'difficult' by speaking up and saying: 'Excuse me, but that's exactly what I said five minutes ago and you didn't seem so enthusiastic then'?

Or just silently assume that he probably was also simply thinking along the same lines and that the chair probably didn't mean to not listen. And then leave it. Yup, she went for the second option, because the first seemed too daunting. Incidentally, "judgements about whether an utterance counts as impolite may be informed by stereotypical beliefs about genderappropriate behaviour" (Mills, 2005, p. 264).

'Leaving it' once because it seems inconsequential, as in the exchange above, can so quickly become the norm. When women attend meetings, the pressure is often to do as everyone else does, right? But this comfortable culture of conformity actually often comes with a bitter aftertaste of unconscious gender bias. Where there is a hierarchical structure and a leader present, women speak up, raise questions, but often feel like they are not being listened to.
The exchange above happened (not at Edinburgh University) within a highly androcentric department of clinical medical research. As Judith Butler observes, gender roles are often "an act that has been going on before one arrived on the scene [and] which has been rehearsed, much as a script survives the particular actors who make use of it, but which require individual actors in order to be actualised and reproduced as reality once again" (Butler, 1988, p. 526).

Other colleagues have spoken of their contributions - and indeed their very presence - going unrecorded in academic minutes or the meeting summary. McConnell-Ginet describes the "persisting under-evaluation of women's work and over-evaluation of men's" (2000, p. 127).

How can this change? Both the leader of the meeting, and the participants, can contribute to creating equal meetings. This recipe suggests what people - men as well as women - can do to ensure that everyone feels safe to contribute to whatever meeting they are at.

It is also helped when the leader of the meeting is aware that this is a present concern, and that there are very real issues of evaluative and unconscious bias. See How to run more equal meetings for some ideas on how the chair can foster a meeting environment where all the voices and contributions are heard and valued. 


\section{Ingredients}

- Agreements/guidelines for meeting behaviour and a protocol for capturing outlier ideas.

- A cool head.

- Useful phrases, gathered from colleagues, observation, imagination, and practised out loud.

- A psychic mirror (or as the Americans put it: "You spot it, you got it") to be aware of your own behaviour and reactions.

- Daybook, pen, paper and ample space (for people to write stuff down if they want to raise something later in the meeting, but someone else is talking).

- Like-minded women for planning an amplification strategy with (see below).

\section{Method}

1. Agree guidelines for the meeting. Ask the chair - preferably beforehand - to start the meeting by inviting participants to co-create guidelines (this is relevant to both situations). These might include:

- $\quad$ No interrupting (except by the chair if someone has spoken long enough).

- No holding separate conversations during the meeting.
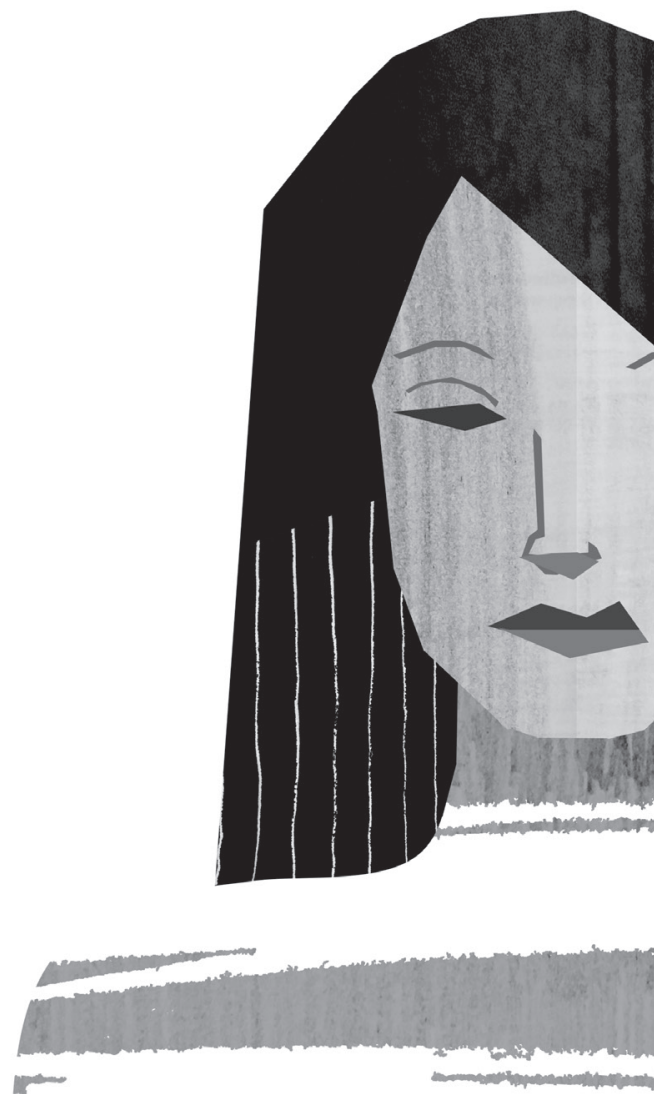

$-$
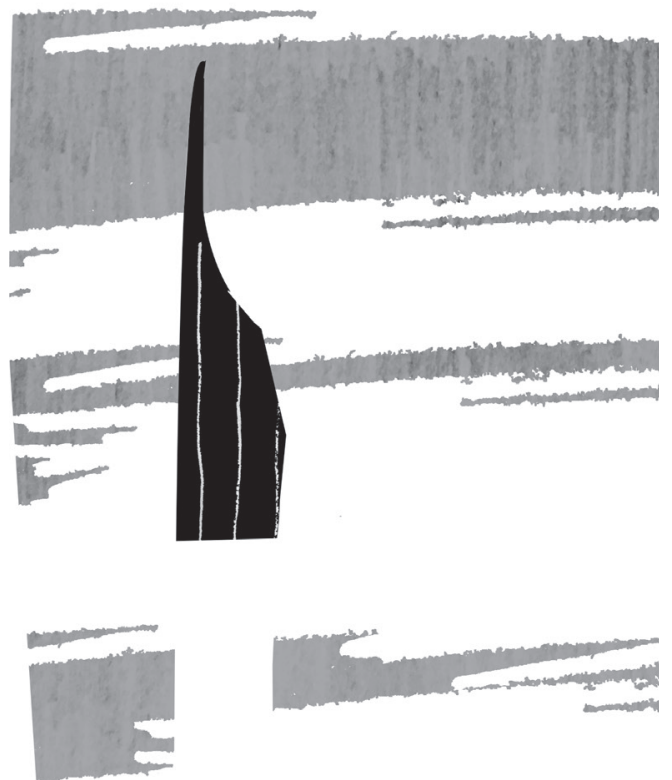
- Women should be respectful to other women too and not disregard them because of gender. Women can hold evaluative bias about other women too.

- Freedom to challenge inappropriate comments and non-verbal interjections such as sighs (which might occur when you go ahead with setting guidelines) with real concerns or facts. For example: "I think we should challenge the stereotype of women being quieter than men - actually take that a step further and ensure that the women contribute equally".

- Such examples work as positive interventions, and using positive language takes the conversation back to fact rather than putting the biased person in the limelight.

2. Make notes of every meeting in a daybook. Especially note who said what, and your own responses as well as other people's. Use the psychic mirror to become aware of your own biases (for help on this, see Challenging bias).

\section{Listen for themes and repeated} behaviours. Try calling it out with a useful phrase such as: "I am noticing that...", "What I am hearing is...", "How might we...?" or more specifically: "Interesting that Bill is feeling
Alice's behaviour is aggressive and unhelpful". Mills (2005) points out that what is heard as aggressive in women's language is often heard as assertive in men's.

4. Claim the space. If you are being ignored, cut-across or silenced, use a combination of body language and words. This method is offered by a consultant colleague: lean forward, put both arms onto the table from elbows to finger tips making a clear territory in front of you, and say: "I would like to make a contribution". Say it clearly and wait until everyone is attentive. Repeat until you are heard (this may take some time). Claim the space and hold it.

5. Be authentic. Resist the temptation to put on a fake smile. The fake smile is a warning sign for one of the authors that she is being 'a good girl' at the expense of the project, sanity and gender balance. And whenever you see it in someone else, they are definitely unhappy - check with them and maybe encourage them to speak up. In her essay Performative Acts \& Gender Constitution, Judith Butler says: "gender is made to comply with a model of truth and falsity which [...] serves a social policy of gender regulation and control. Performing one's gender wrong initiates a set of punishments both obvious and indirect" (Butler, 1988, p. 528). 
Thus the temptation to stay quiet and not be 'punished' can be very strong.

\section{Collaborate with your women \\ colleagues. Use amplification} as described in this article from the Washington Post:

When President Obama took office, two-thirds of his top aides were men. Women complained of having to elbow their way into important meetings. And when they got in, their voices were sometimes ignored. So female staffers adopted a meeting strategy they called "amplification": When a woman made a key point, other women would repeat it, giving credit to its author. This forced the men in the room to recognize the contribution - and denied them the chance to claim the idea as their own. "We just started doing it, and made a purpose of doing it. It was an everyday thing," said one former Obama aide who requested anonymity to speak frankly. Obama noticed, she and others said, and began calling more often on women and junior aides. (Eilperin, 2016)

\section{Warning}

Be aware of people who are biased (unconsciously or consciously); they sometimes don't like to have it pointed out to them. It never works to try to make a biased person change his (or her) mind just before a meeting. Do this in a private one-to-one meeting later. It's hard to argue with bias and prejudice - and before you know it you've lost your cool and are saying things that are inappropriate for a work meeting. 